\title{
Long-term dysphagia due to bronchogenic cyst of the esophagus
}

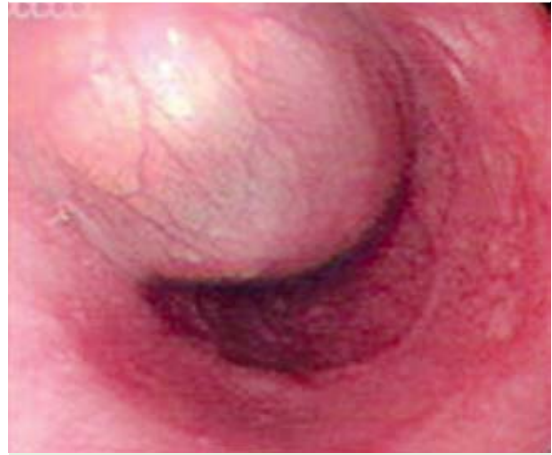

Fig. 1 Upper endoscopy in a 23-year-old woman with progressive dysphagia over the past year, showing a large bulging lesion in the lower third of the esophagus, $30 \mathrm{~cm}$ from the incisors.
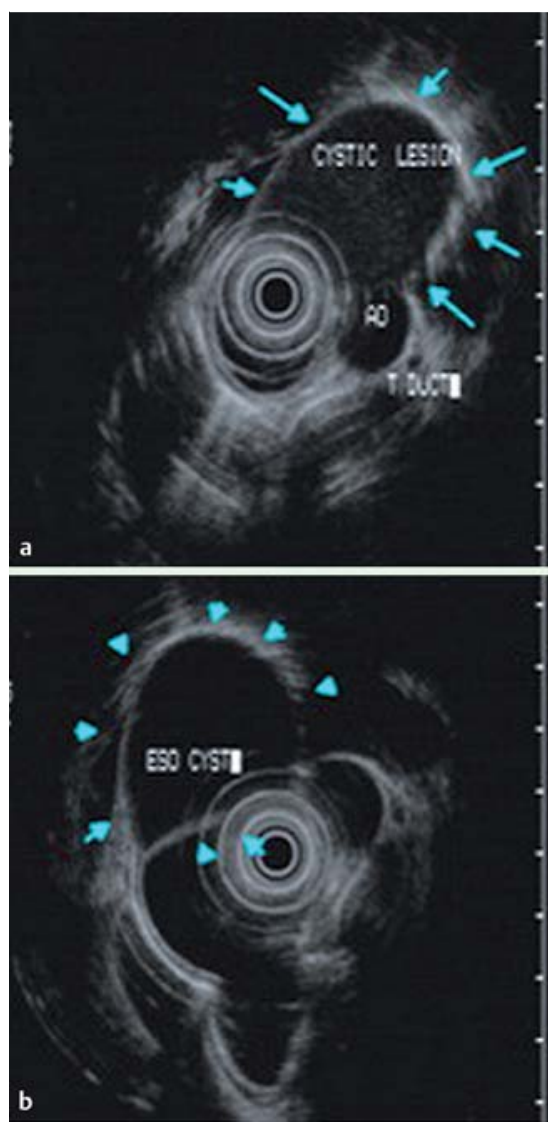

Fig. 2 a, b Endoscopic ultrasound of the esophagus showing a large cystic lesion, $30-35 \mathrm{~cm}$ from incisors.

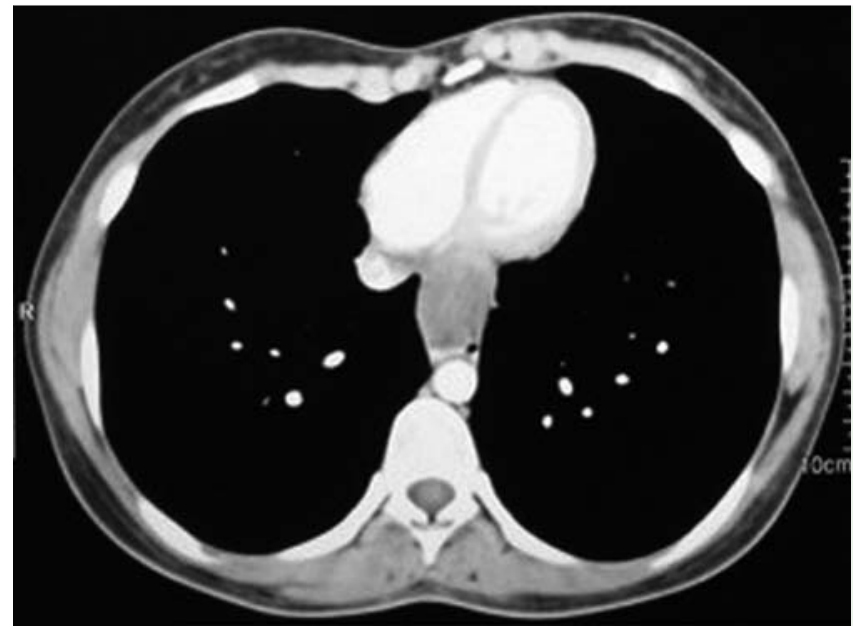

Fig. 3 CT scan of the thorax showing a cystic mass located in the distal part of the esophagus.

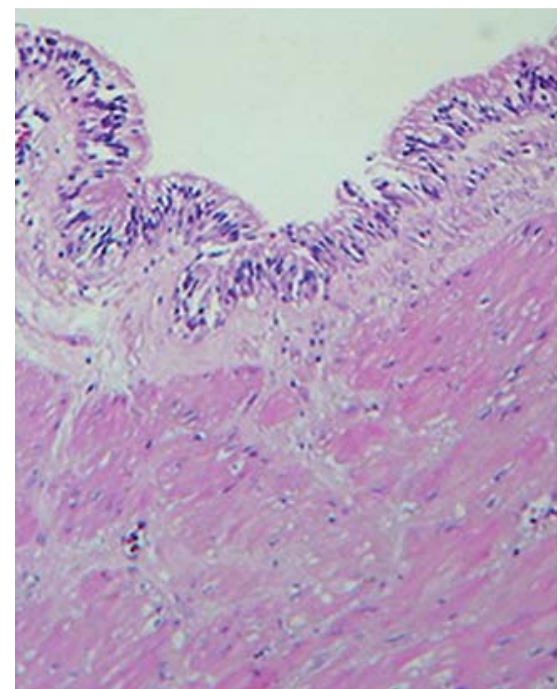

Fig. 4 Microscopic section showing the lining of the cyst wall: note the respiratory ciliated pseudostratified columnar epithelium and smooth muscle.

A 23-year-old woman attended our hospital with the complaint of progressive dysphagia over the past year, especially to solid foods. Upper endoscopy showed a bulging lesion, which was probably due to external pressure on the distal part of the esophagus ( Fig.1). Endoscopic ultrasound (EUS) revealed a $3 \times 3 \mathrm{~cm}$ cystic lesion in the same region, suggestive of a duplication or bronchogenic cyst ( Fig.2). Thoracic computed tomography showed a cystic lesion located in the same region (๑ Fig. 3).
Thoracotomy was carried out and a cystic mass was found between the mucosa and muscular layers of the esophagus, and was completely resected. Pathologic examination revealed respiratory ciliated pseudostratified columnar epithelium overlying smooth muscle in the lining of the cyst wall, compatible with esophageal bronchogenic cyst ( $\nabla$ Fig.4). The patient was asymptomatic on follow-up.

Foregut cysts are a rare developmental anomaly and believed to result from abnormal budding or division of the primitive foregut during development [1]. Bronchogenic cysts are uncommon in adults [1] and the paraesophageal type is rare [2]. In 1948, Maier divided bronchogenic cysts of the mediastinum into the following groups: paratracheal; carinal; hilar; paraesophageal; and miscellaneous [3]. Esophageal bronchogenic cysts predominately affect young women [2], as in our patient. Most patients are asymptomatic although manifestations include dysphagia, chest pain, epigastric pain, cough, and dyspnea [1]. Our patient, however, only had dysphagia. It is difficult to diagnose an intramural esophageal cyst by imaging or even on histological examination [1]. On endoscopy or barium studies, the cysts appear as a protruding submucosal mass. EUS is increasingly used to diagnose mediastinal and esophageal cysts $[4,5]$. Bronchogenic cysts should be surgically resected because surgery can be more complicated and hazardous 
when the cyst is symptomatic [2]. Further advances in EUS may aid in reaching a definite diagnosis before surgery.

Endoscopy_UCTN_Code_CCL_1AF_2AB

Competing interests: None

\section{Ghobakhlou, S. R. Fatemi, A. Abbasi Dezfouli, F. Tirgary, M. R. Zali}

Research Center for Gastroenterology and Liver Diseases, Shahid Beheshti University of Medical Sciences, Tehran, Iran

\section{References}

1 St-Georges R, Deslauriers J, Duranceau A et al. Clinical spectrum of bronchogenic cysts of the mediastinum and lung in the adult. Ann Thorac Surg 1991; 52: 6-13

2 Ko SF, Hsieh MJ, Lin JW et al. Bronchogenic cyst of the esophagus: clinical and imaging features of seven cases. Clin Imaging 2006; 30: $309-314$

3 Maier HC. Bronchogenic cyst of the mediastinum. Ann Surg 1948; 127: 476-502

4 Faigel DO, Burke A, Ginsberg GG et al. The role of endoscopic ultrasound in the evaluation and management of foregut duplications. Gastrointest Endosc 1997; 45: $99-$ 103

5 Lim LL, Ho KY, Goh PM. Preoperative diagnosis of a paraesophageal bronchogenic cyst using endosonography. Ann Thorac Surg 2002; 73: 633-635

\section{Bibliography}

DoI http://dx.doi.org/

10.1055/s-0032-1306791

Endoscopy 2012; 44: E129-E130

(c) Georg Thieme Verlag KG

Stuttgart · New York

ISSN 0013-726X

\section{Corresponding author}

\section{Dr S. R. Fatemi}

Research Center for Gastroenterology and Liver Diseases

Taleghani Hospital

Tabnak Street, Evin

Tehran

Iran

Fax: +98-21-22432515

dr.rfat20@yahoo.com 